\title{
A concepção de um Produto Educacional: do desenvolvimento de atividades em sala de aula à construção de um Blog de Modelagem Matemática
}

\author{
The design of an Educational Product: from the development of classroom \\ activities to the construction of a Mathematical Modeling Blog
}

\begin{abstract}
Elenice Josefa Kolancko Setti ${ }^{1}$
Rodolfo Eduardo Vertuan²

\section{Resumo}

Este artigo tem a pretensão de apresentar o Produto Educacional fruto de uma dissertação de Mestrado Profissional em Ensino de Matemática. A partir da questão de pesquisa que visou investigar quais as contribuições de um trabalho interdisciplinar com Modelagem Matemática no que diz respeito à ressignificação de conceitos matemáticos e à aprendizagem de novos conceitos, desenvolvemos três atividades de Modelagem Matemática com alunos do primeiro ano de um curso técnico integrado ao Ensino Médio. Em seguida, construímos um Blog de Modelagem Matemática para disponibilizar as atividades de Modelagem desenvolvidas e alguns textos sobre Modelagem e Interdisciplinaridade com o objetivo de proporcionar ao professor da Educação Básica um local onde possa tirar dúvidas, amadurecer ideias e compartilhar suas experiências.
\end{abstract}

Palavras-chave: Educação Matemática. Modelagem Matemática. Produto Educacional.

\section{Abstract}

This article intends to present the Educational Product as the result of a Master's dissertation on Teaching Mathematics. From the research question that sought to investigate the contributions of an interdisciplinary work with Mathematical Modeling regarding the re-signification of mathematical concepts and the learning of new concepts, we developed three activities of Mathematical Modeling with first year students of a technical course integrated to the High School. Next, we built a Mathematical Modeling Blog to make available the Modeling activities developed and some texts on Modeling and

${ }^{1}$ Doutoranda do Programa de Pós-Graduação em Educação em Ciências e Educação Matemática da UNIOESTE. Mestre em Ensino de Matemática, pela UTFPR. Docente do Instituto Federal do Paraná, campus Assis Chateaubriand. E-mail: elenicesetti@gmail.com.

2 Doutor. Docente do Curso de Licenciatura em Matemática da UTFPR, Campus de Toledo; do Programa de Pós-Graduação, Mestrado Profissional em Ensino de Matemática da UTFPR, Campus de Londrina e Cornélio Procópio; e do Programa de Pós-Graduação, Mestrado e Doutorado em Educação em Ciências e Educação Matemática da Universidade Estadual do Oeste do Paraná, UNIOESTE, Campus de Cascavel. E-mail: rodolfovertuan@yahoo.com.br. 
Interdisciplinarity with the objective of providing the Basic Education teacher with a place where they can ask questions, mature ideas and share their experiences.

Keywords: Mathematical Educacion. Mathematical Modeling. Educacional Product.

\section{Introdução}

As práticas de Modelagem Matemática como estratégia de ensino de Matemática, vêm sendo, aos poucos, incorporada nas aulas de Matemática. No entanto, observa-se ainda uma resistência por parte de alguns professores e alunos em adotar a Modelagem. Mesmo existindo um movimento expressivo em torno desta perspectiva de ensino, alguns professores da Educação Básica ainda se sentem inseguros e, quando aceitam o desafio de tentar, por vezes desistem frente às primeiras dificuldades e/ou insucessos.

Deste modo, buscou-se elaborar um Produto Educacional de Modelagem Matemática que pudesse auxiliar o professor da Educação Básica na incorporação desta estratégia de ensino nas aulas de Matemática. A partir da pesquisa realizada no âmbito de um Mestrado Profissional em Ensino de Matemática, pensou-se em socializar as atividades de Modelagem desenvolvidas, bem como seus respectivos relatos, particularidades e refinamentos em um Blog de Modelagem.

A pesquisa foi realizada com alunos do primeiro ano do curso técnico em Informática integrado ao Ensino Médio de um Instituto Federal. Tendo como problemática inicial a defasagem e o receio em Matemática dos alunos ingressantes, a pesquisa realizada buscou investigar a seguinte interrogação: Quais são as possíveis contribuições de um trabalho interdisciplinar em Modelagem Matemática no que diz respeito à ressignificação de conceitos matemáticos e à aprendizagem de novos conceitos?

Destacamos 0 aspecto interdisciplinar, visto que 0 trabalho com Modelagem Matemática possibilita esta abordagem e pode contribuir com as especificidades do currículo integrado, além de poder proporcionar ao aluno uma visão ampla do papel da Matemática nos contextos extra-matemáticos. 
A seguir apresentaremos a contextualização da pesquisa que originou 0 produto educacional, suas principais características, relevância e potencial.

\section{Contextualizando}

Historicamente, a efetivação dos processos de ensino e de aprendizagem da Matemática apresenta alguns obstáculos. Dentre eles, está o fato de que, frequentemente, o rol de conteúdos apresentado nas matrizes curriculares da Educação Básica é ensinado sem aplicação ou sem contextualização, sendo mecanicamente reproduzido pelos estudantes, na maioria das vezes, sem qualquer sentido e sem integração com as outras áreas do conhecimento. De acordo com nossas percepções, podemos afirmar que grande parte dos alunos que conclui o Ensino Fundamental, inicia o Ensino Médio sem saber conceitos matemáticos considerados básicos ao seu nível de escolaridade. E ainda, mesmo sabendo alguns algoritmos, frequentemente não possuem ideia de onde são utilizados e qual a lógica de seus funcionamentos.

Nossa experiência sugere que esta situação também tem sido vivenciada no âmbito dos Cursos Técnicos Integrados ao Ensino Médio. Neste contexto, subentende-se que os estudantes devem utilizar a Matemática para resolver problemas de sua área de formação técnica, já que ao concluírem o curso estarão aptos a exercer a profissão. Deste modo, não necessitarão apenas saber técnicas de Matemática, mas, além disso, deverão pensar matematicamente em um contexto, muitas vezes, não matemático. Para isso, a proposta destes cursos é de que o ensino de todas as disciplinas se dê de modo integrado, visando que 0 egresso não seja apenas um técnico, mas que tenha a possibilidade de atuar ativamente na sociedade intervindo em situações que demandem solução. Neste contexto, alguns dos princípios da Educação Profissional Técnica de Nível Médio elencados nas Diretrizes Curriculares Nacionais para a Educação Profissional Técnica de Nível Médio são:

[...] IV - Articulação da Educação Básica com a Educação Profissional e Tecnológica, na perspectiva da integração entre saberes específicos 


\begin{abstract}
para a produção do conhecimento e a intervenção social, assumindo a pesquisa como princípio pedagógico; [...]

$\mathrm{VI}$ - indissociabilidade entre teoria e prática no processo de ensinoaprendizagem;

VII - interdisciplinaridade assegurada no currículo e na prática pedagógica, visando à superação da fragmentação de conhecimentos e de segmentação da organização curricular;

VIII - contextualização, flexibilidade e interdisciplinaridade na utilização de estratégias educacionais favoráveis à compreensão de significados e à integração entre a teoria e a vivência da prática profissional, envolvendo as múltiplas dimensões do eixo tecnológico do curso e das ciências e tecnologias a ele vinculadas [...] (BRASIL, 2012, p. 2).
\end{abstract}

Assim como nos Parâmetros Curriculares Nacionais para o Ensino Médio (2000) e nas Diretrizes Curriculares Estaduais do Paraná (2008), observa-se que as Diretrizes Curriculares Nacionais para a Educação Profissional Técnica de Nível Médio (2012) também atentam para um ensino integrado, contextualizado e interdisciplinar.

No entanto, ainda parece existir nos cursos técnicos integrados de nível médio certa dificuldade em realizar o trabalho segundo estes princípios. Neste contexto, vislumbramos na Modelagem Matemática potencialidades de contribuir para um ensino de Matemática dinâmico, em que os conceitos são desenvolvidos à medida que são necessários no desenvolvimento de investigações de situações problemáticas, que geralmente são de outras áreas do conhecimento, que não a Matemática, possibilitando um trabalho integrado, contextualizado e interdisciplinar.

Desse modo, entendemos que a Modelagem Matemática "constitui uma alternativa pedagógica na qual fazemos uma abordagem, por meio da Matemática, de uma situação-problema não essencialmente Matemática" (ALMEIDA; SILVA; VERTUAN, 2013, p. 17). Assim, há um entendimento que toda atividade de Modelagem Matemática é interdisciplinar. No entanto, a partir de pesquisa realizada em trabalhos de Modelagem Matemática na Educação Matemática publicados em eventos da área ${ }^{3}$, observa-se que há diferentes

${ }^{3}$ Encontro Paranaense de Modelagem em Educação Matemática (EPMEM); Conferência Nacional sobre Modelagem Matemática (CNMEM); International Conference on the Teaching of Mathematical Modelling and Aplications (ICTMA). Estudo apresentado em Setti e Vertuan (2016a; 2016b). 
entendimentos do que seria o trabalho interdisciplinar em Modelagem (Quadro 1), desde a utilização, pelo professor de Matemática, do contexto de outra disciplina, ou área, para desenvolver uma atividade de Modelagem, até o movimento de diferentes disciplinas e seus respectivos professores para o desenvolvimento da atividade de Modelagem, em que o foco é a resolução de um problema ${ }^{4}$.

\begin{tabular}{|c|l|}
\hline CATEGORIA & \multicolumn{1}{|c|}{ CARACTERÍSTICAS } \\
\hline 1 & $\begin{array}{l}\text { Interdisciplinaridade entendida como a contextualização de conceitos da } \\
\text { Matemática que o professor pretende ensinar ou aplicar - o foco está na } \\
\text { matemática. }\end{array}$ \\
\hline 2 & $\begin{array}{l}\text { Interdisciplinaridade entendida como o movimento entre diferentes } \\
\text { disciplinas e seus respectivos docentes que buscam, a partir de seus } \\
\text { referenciais, mediar a resolução de um problema de interesse comum - o } \\
\text { foco está na resolução de um problema via diferentes olhares. }\end{array}$ \\
\hline 3 & $\begin{array}{l}\text { Interdisciplinaridade sendo suscitada em decorrência da necessidade } \\
\text { advinda do desenvolvimento de uma atividade de Matemática. }\end{array}$ \\
\hline 4 & $\begin{array}{l}\text { Interdisciplinaridade sendo desenvolvida em uma disciplina que não seja } \\
\text { Matemática, que utiliza a Matemática como ferramenta de resolução da } \\
\text { situação-problema. }\end{array}$ \\
\hline
\end{tabular}

Quadro 1 - Categorias de Interdisciplinaridade em Modelagem Matemática

Fonte: Adaptado de SETTI (2017).

Neste sentido, reconhecemos o entendimento da interdisciplinaridade como característica inerente à Modelagem Matemática, mas vislumbramos e defendemos àquele entendimento que extrapola a mera ideia de usar conceitos de duas áreas ou disciplinas diferentes, que envolve diferentes professores, planejamento compartilhado, o uso de diferentes conceitos, de tal modo que os alunos possam, em diferentes disciplinas de sua grade curricular, vivenciar a resolução de um problema que "interessa resolver". Para os alunos, nesse caso, o mais importante reside em resolver o problema e não nos conceitos das disciplinas utilizados para isso. Os conceitos das disciplinas são meios para resolver o problema.

Neste contexto é que, nesta pesquisa, desenvolvemos três atividades de Modelagem Matemática, planejadas e realizadas de modo interdisciplinar, em uma turma do primeiro ano do Curso Técnico de Informática Integrado ao Ensino Médio de um Instituto Federal do Paraná. Nosso objetivo de pesquisa consistiu

${ }^{4}$ Resultados publicados em Setti e Vertuan (2016a; 2016b). 
em investigar a existência de contribuições de um trabalho interdisciplinar em Modelagem Matemática no que diz respeito à ressignificação de conceitos matemáticos e à aprendizagem de novos conceitos, analisando as ações dos alunos ao lidarem com os conceitos que emergiram na resolução e inferir acerca das influências das intervenções dos professores ao mediar essas ações no decorrer do trabalho interdisciplinar. A questão de pesquisa sobre a qual lançamos olhares, portanto, foi:

Quais são as possíveis contribuições de um trabalho interdisciplinar em Modelagem Matemática no que diz respeito à ressignificação de conceitos matemáticos e à aprendizagem de novos conceitos?

Para a realização das análises, nos apoiamos nas seguintes questões auxiliares: Quais conceitos matemáticos emergem no desenvolvimento de atividades de Modelagem Matemática no contexto de um trabalho interdisciplinar específico realizado por professores que atuam no primeiro ano do Curso Técnico de Informática Integrado ao Ensino Médio? Quais ações empreendem os alunos ao lidar com esses conceitos matemáticos? Quais as intervenções dos professores, se houveram, ao mediar as ações dos alunos no decorrer do trabalho interdisciplinar? Tomando nosso entendimento de interdisciplinaridade, de que modo ela se expressa nas atividades de Modelagem desenvolvidas?

Os objetivos da pesquisa corroboraram com a "natureza" da dissertação (Mestrado Profissional), que, possui dois focos principais. O primeiro refere-se à elaboração de um produto educacional relacionado à Modelagem Matemática e seu refinamento para fins de divulgação; e o segundo, refere-se à investigação de possíveis contribuições de um trabalho interdisciplinar com Modelagem Matemática no que diz respeito à ressignificação de conceitos matemáticos e à aprendizagem de novos conceitos. De todo modo, estes dois focos são interdependentes, uma vez que é a partir da investigação expressa no segundo, que se pretendeu refinar o produto educacional, para o qual convergiram as ações deste trabalho. 
Neste sentido, a partir da discussão das atividades em torno das aprendizagens dos sujeitos, a nossa intenção foi refinar as atividades de Modelagem (desenvolvidas com esses alunos) e apresentá-las na forma de um Blog de Modelagem, com o objetivo de auxiliar o professor da Educação Básica, que atue em um curso técnico ou não, no trabalho com Modelagem, promovendo a interdisciplinaridade no contexto de cursos técnicos integrados ao Ensino Médio e nos cursos regulares de Ensino Médio.

No entanto, desenvolver um trabalho interdisciplinar em Modelagem Matemática não é simples, pois envolve, além do professor de Matemática, a predisposição de outros professores, de outras áreas. Portanto, embora não seja o nosso foco neste artigo, o que se mostrou relevante na pesquisa foi o interesse e a forma como os professores de outras disciplinas lidaram com a possibilidade de um trabalho interdisciplinar como o que foi desenvolvido para a coleta de dados. Neste trabalho, contudo, embora a participação dos professores tenha acontecido "com o tempo" e, ainda que outros professores tenham atuado em parceria no desenvolvimento das atividades, a coleta de informações se deu nas aulas de Matemática e é sobre as atividades e diálogos que aconteceram nesse espaço que se deram as análises. Todavia, as análises do trabalho de dissertação, embora sejam apresentadas, neste texto, quando relacionadas ao Produto Educacional, não terão aqui foco em si mesmas, dada a intenção o artigo de discutir o Produto Educacional.

A seguir, apresentaremos o processo de desenvolvimento das atividades de Modelagem em sala de aula até a construção do Blog de Modelagem Matemática.

\section{Do desenvolvimento de atividades em sala de aula à construção de um Blog de Modelagem Matemática}

O Mestrado Profissional tem como requisito o desenvolvimento de um Produto Educacional que "possa ser disseminado, analisado e utilizado por outros professores" (MOREIRA; NARDI, 2009, p. 4). Mas como produzir um Produto 
Educacional em Modelagem Matemática que, além de compor um encarte de Atividades de Modelagem, seja um canal de divulgação da Modelagem e ainda, um canal de comunicação entre professores que se dispõem a desenvolver atividades de Modelagem em suas aulas? E como construir um Produto Educacional em Modelagem, considerando as características desta metodologia de ensino e a prerrogativa de que as atividades de Modelagem devem, necessariamente, considerar as especificidades dos contextos em que são desenvolvidas?

Geralmente, a dissertação de um Mestrado Profissional deve ser o "relato de uma experiência de implementação de estratégias ou produtos de natureza educacional" (MOREIRA; NARDI, 2009, p. 4). No entanto, nosso trabalho buscou, a partir da investigação da nossa interrogação de pesquisa, desenvolver um Produto Educacional que atendesse às demandas do desenvolvimento destas práticas. Diante disto, é possível considerar que a pesquisa originou dois produtos educacionais: as atividades de Modelagem Matemática, que foram desenvolvidas, testadas e refinadas para desencadear o segundo produto, o Blog de Modelagem.

Inicialmente, a ideia era desenvolver atividades de Modelagem nas aulas regulares de Matemática (com 2 horas/aulas semanais), interdisciplinarmente com as disciplinas técnicas do curso de informática - Fundamentos de Informática (com 2 horas/aula semanais) e Algoritmos e Linguagem de Programação (com 4 aulas semanais), que eram ministradas pelo mesmo professor. No entanto, durante o planejamento das atividades e do projeto como um todo, optamos por convidar outros professores de diferentes disciplinas para participar do projeto. Deste modo, participaram também os professores de Português e Arte (na primeira atividade), Química, Biologia, Física e Geografia (na terceira atividade).

A intenção de desenvolver as atividades nas aulas regulares é de observar como se daria o desenvolvimento de atividades de Modelagem neste contexto, tendo em vista o número de alunos e a carga horária da disciplina.

Deste modo, foram planejadas e desenvolvidas três atividades de Modelagem Matemática com os alunos do primeiro ano do curso técnico em 
Informática integrado ao Ensino Médio. Como se tratava de curso integrado, tínhamos a preocupação de desenvolver atividades relacionadas com o contexto do curso técnico em questão. Para isto, com exceção da primeira, as atividades foram planejadas e desenvolvidas juntamente com o professor de Informática da turma. A primeira atividade não teve um contexto técnico, mas no seu desenvolvimento, os alunos acabaram utilizando de conceitos/instrumentos da área de informática para conseguir resolver o problema. E ainda, envolveu as professoras de Arte e Português.

As atividades desenvolvidas foram: 1) Qual é o público; 2) De que tamanho vai ficar? e 3) Lixo Eletrônico.

A atividade "Qual é o público?" surgiu de um contexto do livro de Malba Tahan, O homem que Calculava. A partir de um trecho do livro, onde o calculista determina a quantidade de folhas de uma árvore, levantou-se uma discussão sobre a aglomeração de pessoas em locais públicos, como shows e passeatas. Deste modo, a partir da foto de um show da cidade onde se localiza o campus do Instituto, os alunos tinham o objetivo de estimar a quantidade de pessoas presentes no local.

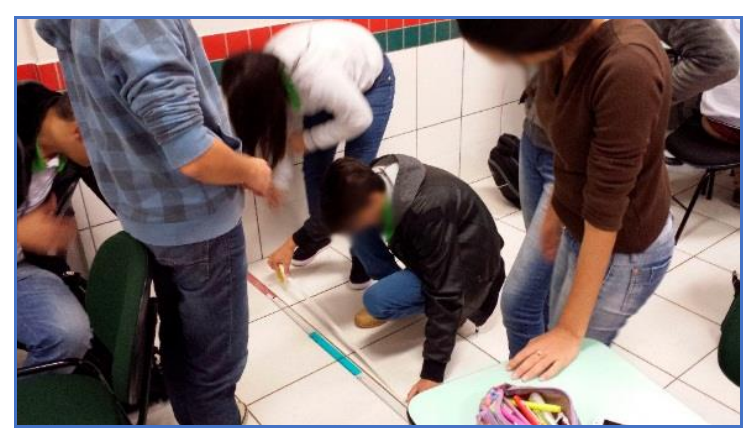

Figura 1 - Alunos medindo os segmentos para formar a região quadrada de 1 metro de lado, com vistas a estimar quantas pessoas cabem em 1 metro quadrado Fonte: arquivos da autora.

$\mathrm{Na}$ atividade “De que tamanho vai ficar?”, os alunos investigaram a diminuição do tamanho dos transístores, componente eletrônico semicondutor responsável pelo controle do fluxo de energia (elétrons) nos processadores 
eletrônicos. A partir de uma tabela com as dimensões dos transístores no decorrer dos anos, os alunos construíram um modelo matemático que descrevia aquela situação e fizeram uma projeção de tamanho para o transístor em 2020. Nesta investigação, o professor de Informática teve uma participação expressiva auxiliando os alunos no conhecimento sobre o componente e o porquê da necessidade de diminuí-lo.

Figura 2 - Registro dos alunos: validação

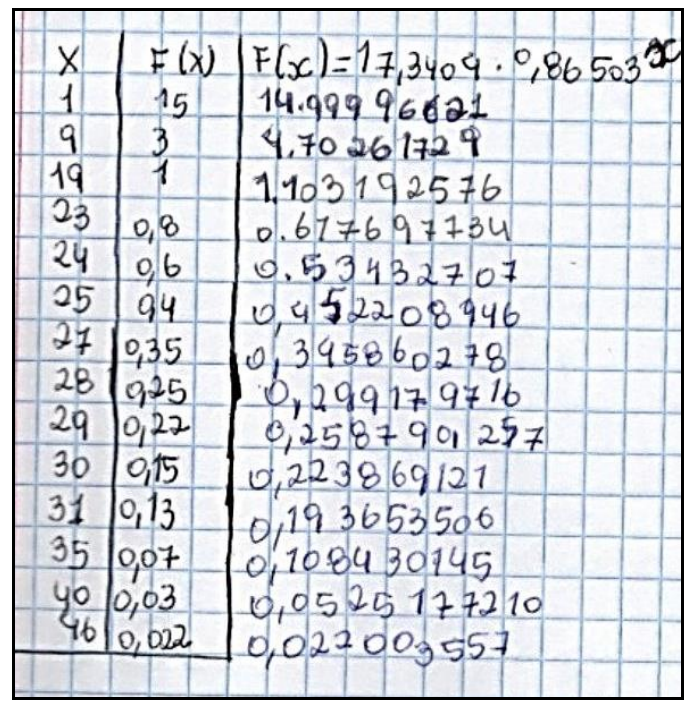

Fonte: registro dos alunos.

Por fim, a atividade "Lixo Eletrônico" investigou, inicialmente, a questão do lixo eletrônico no Brasil, a partir de vídeos e dados encontrados em notícias publicadas na internet. Após a inteiração com o tema, os alunos foram delimitando para a questão dos celulares descartados por eles e em seguida estendendo esta análise para a população da cidade. Por fim, decidimos que era necessário se fazer uma conscientização sobre a questão do lixo eletrônico entre a população. Como se tratava de alunos de um curso técnico em Informática, construíram, com o auxílio do professor da área técnica, sites informativos sobre o lixo eletrônico (Figura 3). 


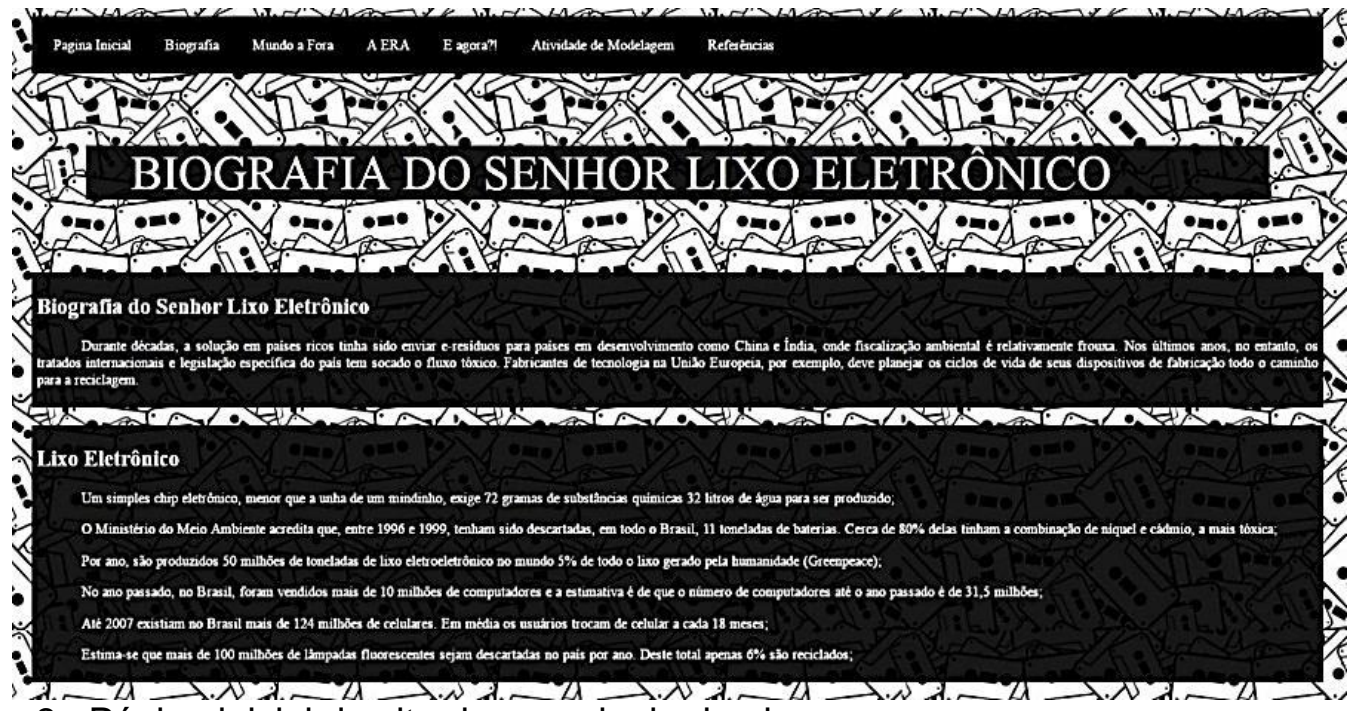

Figura 3 - Página inicial do site de uma dupla de alunos

Fonte: site construído pelos alunos.

As atividades de Modelagem Matemática, bem como a descrição de algumas das resoluções dos alunos e sugestões de encaminhamento para a sala de aula, estão disponíveis no Blog de Modelagem Matemática (Figura 4). Este, por sua vez, tem a pretensão de servir como apoio ao professor que se interessar em trabalhar com Modelagem.

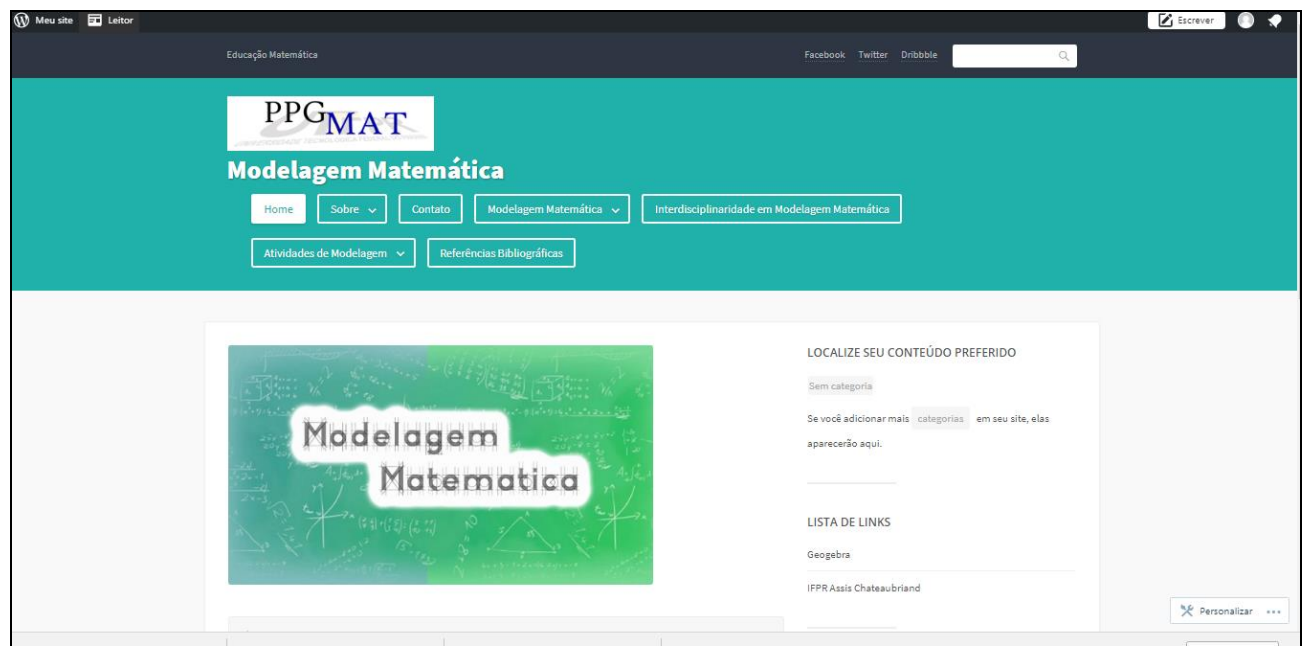

Figura 4 - Página inicial do Site/blog de Modelagem (Produto Educacional) Fonte: modelagemmatematica.wordpress.com. Acesso em: 10/01/2018. 
A página inicial consiste em um espaço para a visualização de posts e, na parte superior da página, localizam-se os menus de acesso: Home, Sobre, Contato, Modelagem Matemática, Interdisciplinaridade em Modelagem Matemática, Atividades de Modelagem, Referências Bibliográficas.

No menu Modelagem Matemática (Figura 5) discorremos, de modo sucinto, sobre Modelagem Matemática na Educação Matemática, com base na pesquisa bibliográfica realizada para a dissertação. Do mesmo modo, procedemos no menu Interdisciplinaridade em Modelagem Matemática. Na página inicial encontra-se um link para a dissertação na íntegra, de modo que os interessados possam se aprofundar na pesquisa.

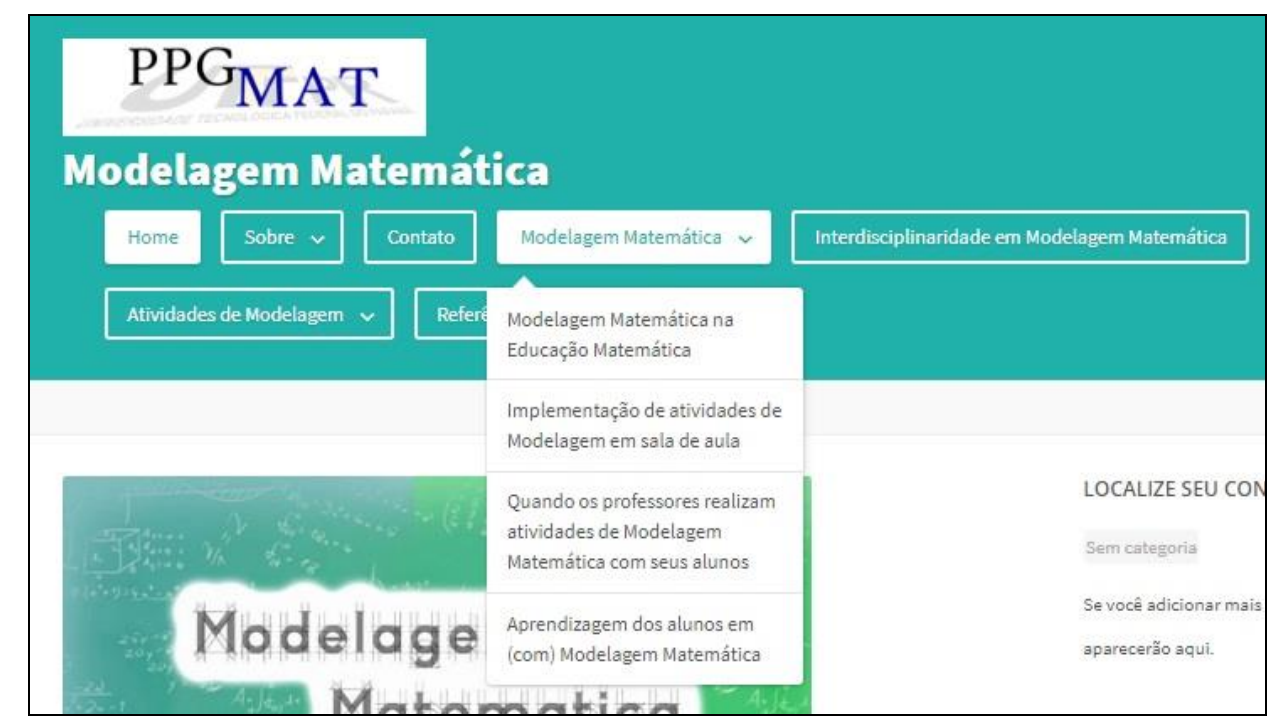

Figura 5 - Menu: Modelagem Matemática Site/blog de Modelagem (Produto Educacional) Fonte: modelagemmatematica.wordpress.com. Acesso em: 10/01/2018.

As atividades desenvolvidas, juntamente com os relatos do desenvolvimento, dicas de encaminhamento, e demais elementos, são disponibilizados no menu Atividades de Modelagem.

Em cada atividade de Modelagem, disponibilizamos (Figura 6):

- Vídeo-convite: trata-se de um vídeo curto contendo informações sobre o tema da atividade de Modelagem Matemática. Tem o objetivo de motivar o grupo de alunos a desenvolver a atividade; 
- A versão da atividade em formato PDF e DOC (a versão .doc visa que o professor possa alterar a situação diante de sua realidade e contexto);

- Uma orientação de encaminhamento da atividade de Modelagem.

- Links relacionados ao tema (materiais, sites, vídeos, etc.);

- Possíveis encaminhamentos: contém tanto os encaminhamentos dos alunos em sala, quanto sugestões de outros encaminhamentos;

- Outros temas, relacionados, passíveis de investigação.

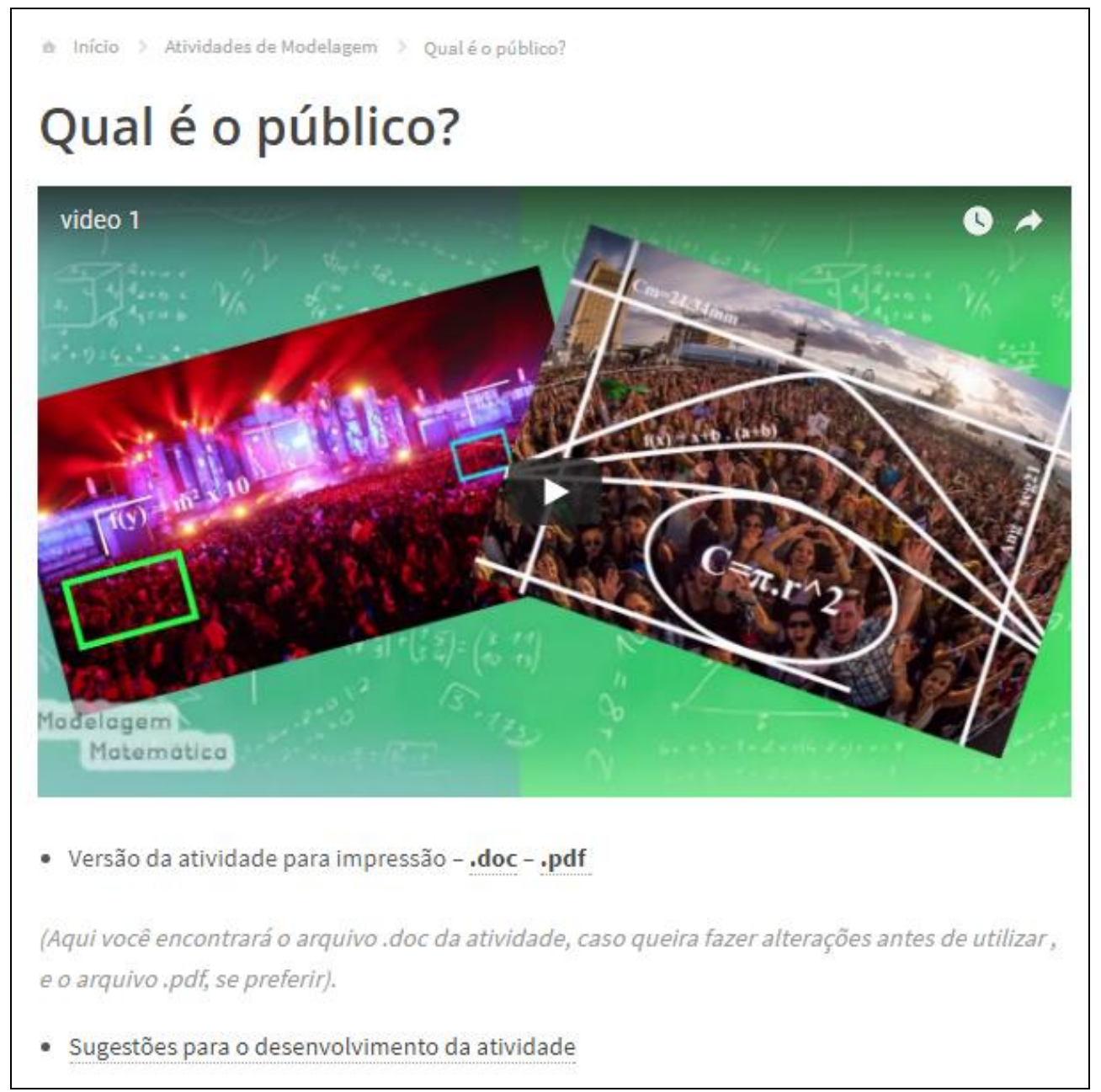

Figura 6 - Parte do blog referente à atividade: Qual é o público (Produto Educacional) Fonte: modelagemmatematica.wordpress.com. Acesso em: 10/01/2018. 
A partir da pesquisa, elencamos algumas observações para o produto educacional, bem como para os docentes que o vierem a utilizar. Por exemplo: é interessante apontar outras possibilidades de encaminhamento das atividades e enfatizar que outras possibilidades surgirão ao desenvolver a atividade em outra turma, pois uma atividade de Modelagem se caracteriza por não haver um único resultado, e sim diferentes encaminhamentos e diferentes abordagens. Por exemplo, na atividade "Qual é o público?", seria interessante que o professor motivasse os alunos a investigar um local de shows de sua cidade, ou de cidades vizinhas, onde os alunos costumam ir. Assim, o encaminhamento poderá ser bem diferente. Como professores iniciantes no trabalho com Modelagem podem acessar o Blog, é importante fornecer dicas de como intervir no desenvolvimento da atividade sem descaracterizá-la, além de um espaço para compartilhar dificuldades, angústias e superações.

Nas atividades desenvolvidas, o uso da tecnologia foi de grande relevância, deste modo, se fez importante criar um tópico no Blog que abordasse o uso da tecnologia digital em sala de aula, bem como disponibilizar links para trabalhos que tratem do tema, assim como links de acesso para download do GeoGebra e de outros softwares que podem ser utilizados no desenvolvimento de atividades de Modelagem.

Em atividades de Modelagem, o papel do professor é de extrema importância, pois é ele quem deve sistematizar os conceitos considerados novos para a turma que emergirem numa atividade de Modelagem. Pois é com a sistematização que o aluno terá condições de utilizar os conhecimentos desenvolvidos na atividade em outras situações. No entanto, deixar claro que em Modelagem, não é o professor falando "para" os alunos, mas sim o professor falando "com" os alunos. E ainda, enfatizar a importância da participação de outros professores no desenvolvimento de atividades de Modelagem. Pois quando o professor de outra disciplina estiver engajado na investigação, o conteúdo pode ser melhor abordado, pois todos os conhecimentos são igualmente importantes, caracterizando assim a interdisciplinaridade vislumbrada. 
Outro aspecto importante que é característico de uma atividade de Modelagem é o modo como os conceitos são abordados. Por exemplo: ao se trabalhar função a partir da demanda de uma atividade de Modelagem, trabalhase diante das características das funções e da influência dos parâmetros numéricos das funções, diferente do modo como geralmente é apresentado aos alunos, pela atribuição de valores à expressão algébrica, construção de tabela e conversão da tabela em gráfico. Assim, o trabalho com função pode passar a ter sentido para o aluno (ALMEIDA; BRITO, 2005).

Por fim, pensou-se em disponibilizar no site um espaço de socialização para os professores, para que possam também compartilhar suas atividades de Modelagem com outros professores. Essa funcionalidade está em fase de implantação, dado que é a partir da divulgação e da legitimação do blog pela comunidade de docentes de Matemática, que outros professores podem apresentar suas produções e empreender discussões.

Algumas destas considerações estão disponíveis no link "Sugestões para o desenvolvimento da Atividade" e outras em links próprios. Tendo em vista estas considerações e toda a pesquisa desenvolvida no decorrer do trabalho, construímos o Blog de Modelagem Matemática na Educação Matemática, que pode ser acessado pelo endereço https://modelagemmatematica.wordpress.com.

\section{Relevância do Produto Educacional}

Foi no desenvolvimento das atividades de Modelagem para a coleta de dados, que se verificou a necessidade de um produto educacional de Modelagem Matemática de fácil acesso aos professores que se dispunham a trabalhar sob esta perspectiva. Isto porque, a professora, primeira autora deste trabalho, possuía, na oportunidade, pouca experiência em práticas de Modelagem e sentiu "na pele" as dificuldades em iniciar este trabalho. Deste modo, acredita-se que o professor da Educação Básica que não está vinculado à programas de PósGraduação, sozinho, pode se ver perdido em suas dúvidas e angústias. Portanto, 
acredita-se que o Blog de Modelagem funcionará como um ambiente para se apresentar dúvidas e buscar ou compartilhar ideias.

Neste contexto, um professor que não tem familiaridade com Modelagem Matemática tem a possibilidade de acessar o Blog e, a partir da leitura dos textos disponíveis no menu Modelagem Matemática, se inteirar das características desta perspectiva de ensino. É possível também realizar as leituras sobre interdisciplinaridade e as possibilidades de um trabalho interdisciplinar com Modelagem Matemática. Em seguida, pode ter acesso às atividades desenvolvidas e seus relatos, podendo amadurecer ideias e desenvolver atividades com seus alunos. Pode, ainda, escolher ir direto às atividades e ver se elas se adequam aos seus objetivos. Isso porque o blog é um produto educacional que dá liberdade aos sujeitos de conhecerem o material de modo linear ou não.

Um aspecto importante é tentar manter um canal de comunicação com estes professores, para termos ideia se estão desenvolvendo atividades de Modelagem, como estão lidando com as possíveis dificuldades e quais foram os resultados. Deste modo, espera-se que muitos professores consigam ter acesso a este Blog, para que então novas práticas de Modelagem possam ser desenvolvidas nas escolas de Educação Básica do país.

\section{Potencial do Produto Educacional}

Para que o Produto Educacional Blog de Modelagem Matemática alcance os objetivos elencados, é necessária sua ampla divulgação. E ainda, que ele não fique estagnado apenas às atividades desenvolvidas para a coleta de dados. Deste modo, o Blog é vinculado a um projeto de pesquisa e extensão que tem o objetivo de desenvolver atividades interdisciplinares de Modelagem com os alunos dos cursos técnicos integrados ao Ensino Médio e ainda, divulgar estas atividades, bem como, o desenvolvimento delas, no Blog de Modelagem. Além disso, o Blog possui um espaço para que os professores possam divulgar suas 
atividades e trocar ideias. Almeja-se, portanto, que em um futuro próximo, essa funcionalidade e intenção do blog sejam efetivados.

\section{Considerações Finais}

Retomando nossa questão de pesquisa - quais são as possíveis contribuições de um trabalho interdisciplinar em Modelagem Matemática no que diz respeito à ressignificação de conceitos matemáticos e à aprendizagem de novos conceitos? - a partir de todo o estudo realizado, entendemos que um trabalho interdisciplinar em Modelagem Matemática apresenta potencialidades significativas em relação à ressignificação de conceitos matemáticos e à aprendizagem de novos conceitos visto que, no desenvolvimento das atividades de Modelagem, conceitos emergiram à medida que foram sendo necessários à resolução do problema. Deste modo, há uma motivação nos alunos em compreender determinado conceito, não apenas um saber por saber, mas saber para realizar algo, e "este algo" sendo próximo de sua realidade, de sua formação profissional, tendo consciência de que os conceitos que se aprende em Matemática têm relação com contextos extra matemáticos, muitas vezes de seu interesse.

Neste sentido, podemos concluir que no desenvolvimento de atividades de Modelagem, os alunos podem aprender novos conceitos matemáticos ou reaprender conceitos um dia já estudados, já que a aprendizagem é sempre provisória e dinâmica, a partir da busca por uma solução para o problema.

Além disso, podemos constatar que, em atividades interdisciplinares em Modelagem Matemática, o aluno tem a oportunidade de desenvolver diferentes aprendizagens como:

- Aprendizagens conceituais, tanto de Matemática como de outras disciplinas ou áreas do conhecimento (VERTUAN; SILVA; BORSSOI, 2017). Como quando compreenderam a funcionalidade do transístor e o porquê da necessidade de diminuir o seu tamanho. 
- Aprendizagens procedimentais, como estratégias de resolução e algoritmos (VERTUAN; SILVA; BORSSOI, 2017). Como quando precisaram calcular a área da região circular e realizar cálculos com logaritmos.

- Aprendizagens de comunicação, ao lidar com conflitos, trabalhar em grupo e justificar suas ideias (VERTUAN; SILVA; BORSSOI, 2017). Como quando apresentavam conceitos ao grupo, e em consenso, o legitimavam ou não.

- Aprendizagens tecnológicas, ao lidarem com softwares de Modelagem, de simulação ou planilhas eletrônicas. Como quando recorreram à pesquisa online, ou ao Google Maps, ou ao GeoGebra.

- Aprendizagens metacognitivas, quando o aluno sabe onde possui dificuldades, no que precisa se dedicar mais, ou desenvolve experiência em resoluções de atividades de Modelagem. Como quando têm consciência de que os conhecimentos sobre funções são insuficientes e buscam novos conhecimentos através de pesquisas ou por intermédio da professora.

Neste sentido, acreditamos que o Blog de Modelagem tem possibilidades de promover o trabalho com Modelagem em diferentes escolas de Educação Básica do país, podendo contribuir para um ensino e aprendizagem de Matemática significativo.

O Produto Educacional Blog de Modelagem Matemática já está disponível no link: https://modelagemmatematica.wordpress.com/, contando com o compartilhamento das três atividades de Modelagem Matemática já apresentadas:

1) Qual é o público?

2) De que tamanho vai ficar?

3) Lixo Eletrônico.

Em breve, disponibilizaremos outras atividades. 


\section{Referências}

ALMEIDA, Lourdes Maria Werle de; SILVA, Karina Pessôa da; VERTUAN, Rodolfo Eduardo. Modelagem Matemática na Educação Básica. 1 ed. São Paulo: Contexto, 2013.

; BRITO, Dirceu dos Santos. Atividades de Modelagem Matemática: Que sentido os alunos podem Ihe atribuir? Ciência e Educação, Bauru, v. 11, n. 3, p. 483498, 2005.

BRASIL. Ministério da Educação. Conselho Nacional de Educação. Câmara da Educação Básica. Diretrizes Curriculares Nacionais para a Educação Profissional Técnica de Nível Médio: Ensino Médio - MEC/SEMTEC. BRASÍLIA: MEC. RESOLUÇÃO № 6, DE 20 DE SETEMBRO DE 2012.

Ministério da Educação. Secretaria de Educação Média e Tecnológica. Parâmetros Curriculares Nacionais para o Ensino Médio. Brasília, 2000.

MOREIRA, Marco Antonio; NARDI, Roberto. O mestrado profissional na área de Ensino de Ciências e Matemática: alguns esclarecimentos. R.B.E.C.T., v.2, n. 3, set./dez. 2009.

PARANÁ, Secretaria de Estado da Educação. Diretrizes curriculares da educação básica: Matemática. Curitiba: SEED, 2008.

SETTI, Elenice Josefa Kolancko. Modelagem Matemática no Curso Técnico de Informática Integrado ao Ensino Médio: um trabalho interdisciplinar. 2017. 261 p. Dissertação (Mestrado Profissional em Ensino de Matemática) - Universidade Tecnológica Federal do Paraná. Londrina, 2017.

; VERTUAN, Rodolfo Eduardo. Que interdisciplinaridade se verifica nos trabalhos de Modelagem Matemática? In: Encontro Paranaense de Modelagem na Educação Matemática, 7, 2016. Londrina: Anais... Londrina: SBEM, 2016a.

Um olhar para a interdisciplinaridade presente nos trabalhos de Modelagem Matemática apresentados nas últimas seis edições da Conferência Nacional sobre Modelagem na Educação Matemática (CNMEM). In: Simpósio Nacional de Ensino e Aprendizagem, 3, 2016. Londrina: Anais...Londrina: UTFPR, 2016b. 